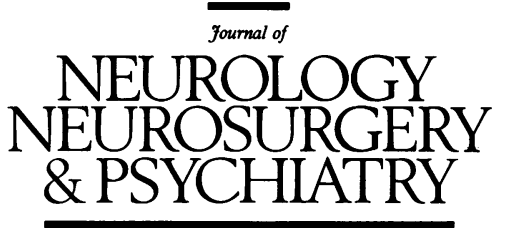

\title{
Editorial
}

\section{Growth factors: potential therapeutic applications in neurology}

Growth factors are defined as signalling proteins required for normal cellular growth and division and, consequently, they are identified as important regulators of developmental processes. In addition, growth factors have a number of potentially important clinical applications, some of which may benefit patients with neurological diseases. This potential was appreciated soon after the purification of nerve growth factor (NGF), ${ }^{1}$ the first member of this group of molecules to be identified. It exerts its predominant effects as a trophic agent for developing sympathetic and sensory neurons, ${ }^{23}$ and, in consequence, it was suggested that NGF deficiency might be relevant to the aetiology of at least one neuronopathy-namely, familial dysautonomia. ${ }^{4}$ A causal relation was not, however, established ${ }^{5}$ and, in the absence of a clear clinical application for treatment with NGF, its functional analysis became the exclusive province of developmental neurobiology for many years. During this period, three NGF homologues were also identified-namely, brain derived neurotrophic factor (BDNF), neurotrophin-3 (NT-3), and neurotrophin-4 $(\mathrm{NT}-4)^{6-9}$; collectively they became known as the neurotrophins and each was shown to exert distinct but overlapping activities within the developing peripheral and central nervous systems. Other growth factors, often initially identified as having systemic activities, were also found to exert significant effects within the developing nervous system. ${ }^{10}$ Molecules with these activities include ciliary neurotrophic factor (CNTF), ${ }^{11}$ leukaemia inhibitory factor/cholinergic differentiation factor (LIF/CDF), ${ }^{12} 13$ the acidic and basic fibroblast growth factors (FGF-1 and FGF-2), ${ }^{14}{ }^{15}$ epidermal growth factor $(\mathrm{EGF}),{ }^{16}$ and platelet derived growth factor (PDGF).$^{17}$

In recent years, there has been renewed interest in determining whether some of these growth factors could be useful therapeutic agents for the treatment of neurological diseases. Clinical trials are currently in progress to determine if they can prevent or protect against neural cell degeneration. This article explores these potential uses for growth factors, with emphasis given to the treatment of peripheral neuropathy, motor neuron disease, Parkinson's disease, Alzheimer's disease, and multiple sclerosis.

\section{Peripheral neuropathy}

Peripheral neuropathy encompasses a large array of diseases subclassified as either neuronopathies, axonopathies, or demyelinating neuropathies according to whether the pathology primarily involves the neuronal cell body, axon, or Schwann cell, although in many neuropathies a combination of pathologies is manifest. ${ }^{18}$ If growth factors are to prove effective treatments for peripheral neuropathy, due consideration must be given to this heterogeneity; for example, growth factors that act predominantly as mitogens for Schwann cells, such as the glial growth factors, ${ }^{19} 20$ are unlikely to be beneficial in the treatment of primary axonopathies. Furthermore, motor, sensory, and autonomic neurons each require different combinations of neurotrophic factors for maintenance of their survival and for axonogenesis. ${ }^{21}$ It is thus likely that, ultimately, a number of growth factors will be used in the treatment of peripheral neuropathy, with the exact therapeutic regimen tailored to the specific clinical presentation. In the meantime, most interest is focusing on the therapeutic role of growth factors in three discrete clinical presentations and most of the preliminary studies have been undertaken with NGF.

Diabetic neuropathy has several manifestations, the most common being a sensory polyneuropathy of insidious onset, due to axonal degeneration..$^{22}$ Neurotrophin deficiency has been hypothesised to be implicated in the pathogenesis of diabetic neuropathy, ${ }^{23}$ and a streptozotocin induced rodent model of diabetic neuropathy exhibits slowed retrograde axonal transport of NGF in sciatic and mesenteric nerves. ${ }^{24}{ }^{25}$ Although these findings do not prove a causal association, one rodent study showed that NGF given three times a week, and immediately after diabetes was induced with streptozotocin, prevented an increase in the tail flick threshold temperature over a three month period, suggesting that NGF may protect against diabetic sensory neuropathy. ${ }^{26}$ As a result, a clinical trial to test the efficacy of NGF as a therapeutic agent for diabetic sensory neuropathy has been started (J A Kessler, personal communication). Clearly, however, there are other important metabolic and vascular pathogenetic mechanisms involved in this neuropathy, suggesting that a combination of treatment strategies will be required to alter its clinical course appreciably.

Neuropathies induced by cytotoxic drugs are potentially well suited to therapeutic intervention with growth factors because treatment can be coadministered with the causative agent. This strategy has the potential to prevent the dose limiting neurotoxicity of some important cytotoxic agents. One example is taxol, used in the treatment of solid tumours such as malignant melanoma and ovar- 
ian carcinoma, which induces a sensory neuropathy ${ }^{27}$ by promoting the abnormal assembly of microtubules within the cytoplasm. ${ }^{28}$ It has been shown that NGF can induce coordinate microtubule assembly ${ }^{29}$ and, consequently, it might be of use in ameliorating such microtubule associated pathology. ${ }^{30}$ Indeed, animal studies have shown either prevention or delay of neuropathic changes when NGF is coadministered with taxol, ${ }^{31}$ vinblastine, ${ }^{32}{ }^{33}$ and cisplatin. ${ }^{34}$ It is postulated that NGF protects against the microtubule associated pathology in taxol and vinblastine toxicity but, in the case of cisplatin, the mechanism of action is unknown. It is now opportune to assess whether growth factors are also useful in preventing neuropathy induced by cytotoxic drugs in patients.

Peripheral nerve injuries may also be amenable to treatment with growth factors. The mRNAs of NGF, $\mathrm{BDNF}, \mathrm{CNTF}$, and $\mathrm{LIF} / \mathrm{CDF}$ are all increased after peripheral nerve lesion in animal models, although they display differing and complex patterns of expression within Schwann cells around the injury site ${ }^{35-39}$; NGF, BDNF, CNTF, and LIF/CDF have all potentiated neuronal survival in neonatal rodent studies after peripheral nerve lesions..$^{40-44}$ Detailed studies in the adult, assessing the degree of peripheral axonal regeneration after treatment with growth factor, need to be conducted before the potential applicability of this strategy to peripheral nerve injury can be adequately assessed.

\section{Motor neuron disease}

The diseases of the motor system comprise a number of discrete and often fatal disorders, grouped together because they share the common pathological process of progressive motor neuronopathy. ${ }^{45}{ }^{46}$ Major insights into motor neuron cell biology have occurred in recent years and, in particular, an understanding of the potential role that specific growth factors play in supporting motor neuron development has been gained. It has been postulated that these same growth factors might ameliorate the devastating effects of motor neuron disease.

The relevant background studies show that CNTF, although not required for normal motor neuron development, ${ }^{47}$ supports the in vitro and in vivo survival of superfluous motor neurons that would normally die in embryogenesis, during the period of neuronal modelling ${ }^{48-50}$; CNTF also prevents the degeneration of axotomised motor neurons in the perinatal rodent, ${ }^{5152}$ and attenuates the decline in motor performance and neuropathology of the pmn/pmn mouse. ${ }^{51}{ }^{52}$ It remains to be established, however, if the results seen in the $p m n$ mouse are relevant to motor neuron disease, as the mouse exhibits a dying-back axonopathy, rather than primary neuronal degeneration..$^{53}$ Nevertheless, it has been reported that disruption of the CNTF gene results in a limited but significant degeneration of facial nerve motor neurons in adult mice, suggesting that CNTF, produced by Schwann cells, ${ }^{54}$ plays a part in the maintenance of rodent motor neurons during postnatal life. By contrast, CNTF deficiency does not seem to be causally related to neurological disease in humans, as a recently identified null mutation of the CNTF gene is equally distributed in a normal cohort and in patients with neurological disease. ${ }^{55}$ This does not preclude a therapeutic role for exogenous CNTF in pathological states such as motor neuron disease, and in concordance with this, two independent clinical trials, each giving systemic CNTF, have been established. It is important to note, however, that analysis of the pharmacokinetics of CNTF emphasises that its short half life, together with its induction of acute phase responses in liver, may limit the clinical usefulness of CNTF given systemically. ${ }^{56}$
The growth factor LIF has structural similarities to CNTF and its cognate receptor shares subunits with the CNTF receptor. ${ }^{57}$ It is thus not surprising to find that LIF also promotes the survival of embryonic spinal cord motor neurons in vitro. ${ }^{559}$ It is also retrogradely transported by motor neurons, especially after injury, ${ }^{39}$ and its mRNA is expressed in muscle during development and in the distal segments of axotomised adult sciatic nerves. ${ }^{39}{ }^{60}$ In vivo, LIF has been shown to rescue neonatal rat motor neurons from death in two independent axotomy studies. ${ }^{4161}$ The systemic administration of LIF to rodents has, however, led to undesirable side effects, ${ }^{62}$ suggesting that careful consideration will need to be given to the dosage and route of administration, if it is to be clinically useful.

Nerve growth factor does not exert any effect on motor neurons but other members of the neurotrophin family do have significant effects and, as such, represent candidate therapeutic agents for motor neuron disease. For example, BDNF, NT-3, and NT-4 all promote the survival of cultured embryonic rat motor neurons and the high affinity receptors for these factors, trkB and trkC, are present on motor neurons, indicating that the neurotrophins act directly on the motor neuron pool. ${ }^{6364}$ Furthermore, the mRNAs of BDNF and NT-3 are expressed by skeletal muscle, both at the time of synaptogenesis and in the adult, suggesting that they may act as target derived growth factors for motor neurons in vivo. ${ }^{6465}$ Also, BDNF is retrogradely transported by perinatal and adult motor neurons and the expression of BDNF mRNA in adult animals is upregulated in denervated muscle, ${ }^{4366}$ further supporting the hypothesis that it is important in maintaining motor neuron integrity. Most importantly, BDNF reduces motor neuron death in neonatal rats after either facial nerve or sciatic nerve axotomy ${ }^{384363}$ and, in a murine deletion mutant of trkB, there is loss of both cranial and spinal motor neurons. ${ }^{67}$ It is of particular note, however, that BDNF null mutant mice do not exhibit a reduction in motor neuron number, ${ }^{68}$ raising the possibility that NT-4, which also acts through the $t r k \mathrm{~B}$ receptor, ${ }^{69}$ could be responsible for promoting motor neuron survival in vivo.

Factors FGF-2 and FGF-5 have also been shown to promote the survival and neuritic extension of chick spinal cord motor neurons. ${ }^{70}$ In recent studies, however, neither FGF-1 nor FGF-2 prevented lesion induced facial motor neuron death in newborn rodents. ${ }^{61}$ Finally, insulin like growth factor-1 (IGF-1) has been shown to be an effective survival factor for rodent motor neurons, both in vitro and in vivo. ${ }^{61}$

Clinical trials are proceeding to test the safety and potential efficacy of BDNF and IGF-1 for the treatment of patients with motor neuron disease. Preliminary reports from one of the CNTF trials indicate that there were serious side effects from treatment, and that a significant number of these patients had fared worse, as assessed by loss of muscle strength, than the control group. ${ }^{71}$

\section{Parkinson's disease}

The characteristic loss of nigral dopaminergic neurons in Parkinson's disease has stimulated the search for neurotrophic factors that support the survival of dopaminergic neurons in vitro. One such molecule is BDNF, in that it supports the survival of cultured foetal dopaminergic neurons. ${ }^{72}$ The detection of mRNA for the BDNF receptor in the substantia nigra, ${ }^{73}$ the isolation of a BDNF like protein from the striatum, ${ }^{74}$ and the demonstration of retrograde axonal transport of radiolabelled BDNF from the 
striatum to the substantia nigra ${ }^{75}$ are all consistent with a putative role of BDNF as a growth factor for nigral dopaminergic neurons. The survival of midbrain dopaminergic neurons is not affected, however, in mutant mice lacking BDNF. ${ }^{68}$ Furthermore, a detailed study by Knusel and colleagues failed to show that BDNF alone could rescue lesioned nigral dopaminergic neurons in an in vivo model in the adult rat. ${ }^{76}$ Despite this result, there is independent evidence that exogenous BDNF modulates dopaminergic activity in the adult rat brain, ${ }^{77}$ suggesting that BDNF might yet prove to be clinically useful in the context of parkinsonism.

The isolation of neurotrophic factor derived from a glial cell line (GDNF) has provided renewed hope that dopaminergic neuron specific neurotrophic factors will be identified. ${ }^{78}$ Firstly, GDNF mRNA is present in striatal dopaminergic target areas of the developing rat brain. ${ }^{79}$ Secondly, GDNF promotes the survival, differentiation, and high affinity dopamine uptake of cultured foetal dopaminergic neurons ${ }^{78}$ but unlike BDNF, NT-3, and $\mathrm{NT}-4 / 5$, it has no effect on cultured nigral derived GABAergic neurons. It also potentiates the survival of dopaminergic neurons in grafts of foetal mesencephalon transplanted to the anterior eye chamber. ${ }^{79}$ This finding suggests that GDNF might be useful in potentiating the survival of mesencephalic grafts transplanted for therapeutic purposes into the forebrain of patients with Parkinson's disease.

Although the evidence suggests that GDNF is a trophic agent for developing dopaminergic neurons, GDNF has not been detected by the method of in situ hybridisation in adult rat brain, suggesting that GDNF may not be a physiologically relevant molecule in the adult. Despite this lack of expression, in vivo studies giving exogenous GDNF are encouraging, suggesting that either GDNF or a related molecule may be a useful therapeutic agent for Parkinson's disease. Firstly, injection into the substantia nigra results in enhanced tyrosine hydroxylase activity locally at the injection site, as well as distally in the ipsilateral striatum. ${ }^{80}$ Secondly, electron microscopic examination at the injection site showed short lived axonal sprouting and synapse formation. ${ }^{80}$ Thirdly, GDNF injection into the substantia nigra of adult rats results in increased motor activity, although this effect is seen with high doses only. ${ }^{81}$ Preliminary studies are also underway to evaluate the effects of GDNF on the recovery of adult rats from 6-OH dopamine lesioning of the nigrostriatal pathway.

Many mitogenic factors that primarily stimulate glial cells have been reported to promote the survival and differentiation of nigral dopaminergic neurons. This list includes FGF-2, ${ }^{82}{ }^{83}$ IGF-1, ${ }^{84}$ transforming growth factor$\alpha{ }^{85}$ and EGF. ${ }^{86}$ The mitogenic subgroup of dopaminergic neurotrophic factors all share the clinically undesirable side effect, however, of promoting glial cell proliferation. By contrast, GDNF and BDNF do not stimulate gliosis and thus are more likely to represent useful therapeutic agents for Parkinson's disease.

\section{Alzheimer's disease}

The neuropathology of Alzheimer's disease includes pathognomonic features (neurofibrillary tangles and amyloid plaques) as well as widespread cortical atrophy and diminished levels of multiple neurotransmitters within the neocortex. ${ }^{8788}$ Despite these extensive abnormalities, some investigators have espoused the view that the demise of cholinergic forebrain neurons is central to the clinical presentation of Alzheimer's disease, raising the possibility that treatment with growth factors could be useful. This view is supported by an extensive literature, which suggests that NGF is a neurotrophic factor for these neurons. Firstly, NGF protein and mRNA have been detected in hippocampal and cortical neurons, ${ }^{89}$ the projection fields of forebrain cholinergic neurons. Secondly, the low affinity NGF receptor is colocalised with choline acetyl transferase (ChAT), ${ }^{84}$ the neurotransmitter phenotype specific enzyme for basal cholinergic neurons, and trk mRNA encoding the high affinity NGF receptor also has been identified in the basal forebrain..$^{90}$ Thirdly, there is selective retrograde transport of labelled NGF from either the neocortex or hippocampus to the basal forebrain nuclei. ${ }^{66}$ It is important to note, however, that a recent report characterising a null mutation of the NGF gene failed to show a reduction in basal forebrain neurons, despite a reduction in ChAT levels; this suggests that the physiological function of NGF in the CNS may be to support neurotransmitter phenotype rather than to act primarily as a trophic agent.91

The efficacy of NGF in mediating basal forebrain neuronal rescue has been studied extensively in CNS axotomy models, performed in mammals ranging from rodents to non-human primates. ${ }^{92} 93$ Transection of the fimbria-fornix, the axonal projection of the cholinergic forebrain nuclei to the hippocampus, results in the death of a substantial number of cholinergic neurons, potentially mimicking the cholinergic neuronal loss seen in Alzheimer's disease. Treatment with $\mathrm{NGF}^{94-98}$ or transplantation of cell lines genetically engineered to secrete $\mathrm{NGF}^{99}$ have been reported to result in cholinergic cell rescue and axonal arborisation. BDNF used in the same fimbria-fornix axotomy model is reported to rescue a smaller number of cholinergic neurons, as well as noncholinergic neurons. ${ }^{76} \mathrm{~A}$ third molecule reported to be effective in cell rescue in this axotomy model is FGF-2, ${ }^{100}$ but, unlike the effects mediated by either NGF or BDNF, its effect is thought to be indirect.

To date, there is only a single case history reporting the testing of NGF as a putative therapeutic agent for Alzheimer's disease ${ }^{101}$; unfortunately, the patient developed an intercurrent illness, necessitating cessation of treatment and making it impossible to assess the long term efficacy of NGF. Even if NGF proves to be an effective therapeutic agent in Alzheimer's disease, it almost certainly will not provide definitive treatment, as pathogenetic mechanisms other than neurotrophin deficiency are clearly involved, and the pathology is clearly not restricted to NGF responsive neurons.

\section{Multiple sclerosis}

Multiple sclerosis is traditionally classified as an autoimmune disease that causes periaxial demyelination by specifically targeting oligodendrocyte ${ }^{102}$ and recent interest has centred on the part that the immunomodulatory cytokine, $\beta$-interferon, can play in diminishing the frequency of recurrent attacks. ${ }^{103104}$ Also, growth factors could potentially subserve a restorative function in multiple sclerosis, by enhancing oligodendrocyte replenishment and, therefore, remyelination. It has been reported that there is a small steady state turnover of non-neuronal cells, including oligodendrocytes, within the normal adult rodent brain. ${ }^{105}$ It is possible that in multiple sclerosis the demands on this physiological process are increased and ultimately perturbed, consistent with the finding that the capacity to replenish lost oligodendrocytes is less in patients with long term multiple sclerosis than in patients with recent onset demyelination. ${ }^{106}$ Functional oligodendrocyte replenishment could be achieved by potentiating either the survival or, theoreti- 
cally, the division of pre-existing oligodendrocytes, as reported to occur in vitro with NGF stimulation. ${ }^{107}$ It also may be possible to upregulate the division and subsequent differentiation of oligodendrocytic progenitor cells, ${ }^{108}$ which persist into adult life. ${ }^{109}$ In vitro data with rodent cells suggest that the proliferative potential of neonatal oligodendrocytic progenitors can be enhanced by PDGF, ,110-111 FGF-2, ${ }^{112-114}$ and NT-3.115

The challenge, if growth factors are to be useful for patients with multiple sclerosis, is to discover how to regulate the proliferative and differentiative potential of progenitor cells without depleting progenitor cell numbers. Recently, enhanced generation of oligodendrocytes has been reported after culture with either CNTF or LIF, ${ }^{116}$ and continued proliferation of their progenitors can be induced in culture with FGF-2 ${ }^{113}{ }^{114}$; together, these findings suggest that, ultimately, either the combined or sequential administration of cytokines could represent useful treatment. Expanded populations of progenitors have also been transplanted into animals with demyelinating lesions and the engrafted cells migrate significant distances, differentiate and myelinate in vivo. ${ }^{117}$ It is uncertain if this strategy will be applicable to the long term treatment of a multifocal disease, such as multiple sclerosis.

\section{Conclusion}

In this article, we have presented an optimistic view of the potential therapeutic uses of growth factors in selected neurological diseases, where definitive treatments are currently lacking. Although there is an extensive body of literature on the basic neurobiology of growth factors, much more study is required to bring these potential therapeutic agents into the clinic as established treatments. Disappointingly, the hope that growth factors will alter the clinical course of fatal neurodegenerative disease has been tempered with the recent report of lack of efficacy and adverse side effects when CNTF was given to patients with motor neuron disease. This failure highlights important issues, which were also considerations when the neurobiology of CNTF was being assessed. Firstly, many of the animal models currently available are, at best, poor approximations to the corresponding human neurodegenerative diseases; yet animal studies are a crucial and necessary step before clinical trials. Secondly, pharmacokinetics need to be thoroughly investigated, to ensure both effective delivery of the growth factor to the site of disease and to minimise unwanted systemic or neurological side effects.

The potential clinical application of growth factors to neurological disease parallels the use of other factors, such as colony stimulating factors, in haemato-oncology, where they are now used to induce bone marrow precursor cells to replenish peripheral blood cells in patients with marrow aplasia. ${ }^{118}$ As a corollary, it is tempting to speculate that recently described precursor cells, found to exist in the adult mammalian brain, ${ }^{119} 120$ could be eventually induced, by the use of exogenous growth factors, to replace dead neurons in a variety of neurological diseases. The more immediate aim is to use either single or combinations of growth factors to protect neural cells or to enhance axonal regeneration. If this can be achieved, growth factors will have assumed an important place in clinical neurology.

We thank Dr Perry Bartlett for many helpful comments and fruitful discussions. In particular, we thank him for introducing us all to the field of neurotrophic factors during our doctoral studies at the Walter and Eliza Hall Institute of Medical Research. We also thank Drs D Weinstein and C Price for reviewing the manuscript and Drs D Price and J Kessler for providing us with personal communications.
JD is a Basser Fellow of the Royal Australasian College of Physicians. TJK is a Howard Hughes Medical Institute Physician Research Fellow. SAK and PST are postgraduate research scholars of the National Health and Medical Research Council of Australia.

All authors contributed equally to this manuscript.

J DRAGO

National Institutes of Health,

Laboratory of Mammalian Genes and Development,

Bethesda, Maryland 20892, USA

The Salk Institute for Biological Studies,

10010 Nth Torrey Pines Road,

La folla, California 92037, USA

T J KILPATRICK

The Walter and Eliza Hall Institute of Medical Research,

S A KOBLAR

Post Office, Royal Melbourne Hospital 3050,

Australia

Correspondence to: Dr S A Koblar.

1 Cohen S. Purification of a nerve-growth promoting protein from the mouse salivary gland and its neuro-cytotoxic antiserum. Proc Natl Acad Sci USA 1960;46:302-11.

2 Levi-Montalcini R, Booker B. Destruction of the sympathetic ganglia in mammals by an antiserum to a nerve-growth protein. Proc Natl Acad Sci USA 1960;46:384-91.

3 Johnson Jr. EM, Gorin PD, Brandeis LD, Pearson J. Dorsal root ganglion neurons are destroyed by exposure in utero to maternal antibody to nerve growth factor. Science $1980 ; 210: 916-8$.

4 Pearson J, Axelrod F, Dancis J. Trophic functions of the neuron. V. Familial dysautonomias. Current concepts of dysautonomia. Ann NY Acad Sci 1974;228:288-300.

5 Breakefield XO, Orloff G, Castiglione C, Coussens L, Axelrod FB, Ullrich A. Structural gene for B-nerve growth factor not defective in familial dysautonomia. Proc Natl Acad Sci USA 1984;81:4213-6.

6 Barde Y-A, Edgar D, Thoenen H. Purification of a new neurotrophic factor from mammalian brain. $E M B O \mathcal{f} 1982 ; 1: 549-53$

7 Leibrock J, Lottspeich F, Hohn A, et al. Molecular cloning and expression of brain-derived neurotrophic factor. Nature 1989;341:149-52.

8 Hohn A, Leibrock J, Bailey K, Barde Y-A. Identification and characterization of a novel member of the nerve growth factor/brain-derived neurotrophic factor family. Nature 1990;344:339-41.

9 Hallbook F, Ibanez CF, Persson H. Evolutionary studies of the nerve growth factor family reveal a novel member abundantly expressed in growth factor family reveal a novel mem

10 Bartlett PF, Drago J, Kilpatrick TJ, Richards LJ, Wookey P, Murphy M. Regulation of the early development of the nervous system by growth
factors. In: Sharma C, Goffinet A, eds. Development of the vertebrate nervous system. London: Academic Press, 1992:1-21.

11 Stockli K, Lottspeich F, Sendtner M, et al. Molecular cloning, expression and regional distribution of rat ciliary neurotrophic factor. Nature 1989; 342:920-3

12 Hilton DJ, Nicola NA, Metcalf D. Purification of a murine leukaemia inhibitory factor from Krebs ascites cells. Anal Biochem 1988;173: 359-67.

13 Hilton DJ, Nicola NA, Gough NM, Metcalf D. Resolution and purification of three distinct factors produced by Krebs ascities cells which have differentiation-inducing activity on murine myeloid leukemic cell lines. $\mathcal{F}$ Biol Chem 1988;263:9238-43.

14 Esch F, Baird A, Ling N, et al. Primary structure of bovine pituitary basic fibroblast growth factor (FGF) and comparison with the aminoterminal sequence of bovine brain acidic FGF. Proc Natl Acad Sci USA terminal sequence

15 Gimenez-Gallego G, Rodkey J, Bennett C, Rios-Candelore M, DiSalvo J, Thomas K. Brain-derived acidic fibroblast growth factor: complete amino acid sequence and homologies. Science 1985;230:1385-8.

16 Cohen S. The stimulation of epidermal proliferation by a specific protein (EGF). Dev Biol 1965;12:394-407.

17 Hammacher A, Hellman U, Johnsson A, et al. A major part of plateletderived growth factor purified from human platelets is a heterodimer of one $A$ and one B chain. F Biol Chem 1988;263:16493-8.

18 Thomas PK, Ochoa J. Clinical features and differential diagnosis. In: Dyck PJ, Thomas PK, Griffin JW, Low PA, Poduslo JF, eds. Peripheral neuropathy. Vol 2. Philadelphia: WB Saunders, 1993:749-74.

19 Lemke GE, Brockes JP. Identification and purification of glial growth factor. $\mathcal{F}$ Neurosci, 1984;4:75-83.

20 Goodearl ADJ, Davis JB, Mistry K, et al. Purification of multiple forms of glial growth factor. $\mathcal{F}$ Biol Chem 1993;268:18095-102.

21 Korsching $S$. The neurotrophic factor concept: a reexamination. $f$ Neurosci 1993;13:2739-48.

22 Thomas PK, Tomlinson DR. Diabetic and hypoglycemic neuropathy. In: Dyck PJ, Thomas PK, Griffin JW, Low PA, Poduslo JF, eds. Peripheral neuropathy. Vol 2. Philadelphia: WB Saunders, 1993:1219-50.

23 Eeuropathy. Vol 2. Philadelphia: WB Saunders, 1993:1219-50.

24 Jakobsen J, Brimijoin S, Skau K, Sidenius P, Wells D. Retrograde axonal transport of transmitter enzymes, fucose-labeled protein, and nerve transport of transmitter enzymes, fucose-labeled protein, and nerve

25 Schmidt RE, Plurad SB, Saffitz JE, Grabau GG, Yip HK. Retrograde axonal transport of 125 I-nerve growth factor in rat ileal mesenteric axonal transport of ${ }^{125}$ I-nerve growth factor in rat ileal mese
nerves-effect of streptozocin diabetes. Diabetes 1985;34:1230-40.

26 Apfel SC, Arezzo JC, Brownlee M, Federhoff H, Kessler JA. Nerve growth factor treatment ameliorates diabetic sensory neuropathy [abstract]. Diabetes 1992;41(suppl):140A.

27 Lipton R, Apfel S, Dutcher J, et al. Taxol produces a predominantly sensory neuropathy. Neurology 1989;39:368-73.

28 Schiff PB, Horowitz SB. Taxol stabilizes microtubules in mouse fibroblast cells. Proc Natl Acad Sci USA 1980;70:1561-6.

29 Drubin DG, Feinstein SC, Shooter EM, Kirschner MW. Nerve growth factor-induced neurite outgrowth in PC12 cells involves the coordinate 
induction of microtubule assembly and assembly-promoting factors. $\mathcal{F}$ Cell Biol 1985;101:1799-807.

30 Peterson ER, Crain SM. Nerve growth factor attenuates neurotoxic effects of taxol on spinal cord-ganglion explants from fetal mice. Science 1982;217:377-9.

31 Apfel SC, Lipton RB, Arezzo JC, Kessler JA. Nerve growth factor prevents toxic neuropathy in mice. Ann Neurol 1991;29:87-90

32 Menesini-Chen MG, Chen JS, Calissano P, Levi-Montalcini R. Nerve growth factor prevents vinblastine destructive effects on sympathetic growtia in newborn mice. Proc Natl Acad Sci USA 1977;74:5559-63.

33 Johnson Jr EM. Destruction of the sympathetic nervous system in neonatal rats and hampsters by vinblastine: prevention by concomitant natal rats and hampsters by vinblastine: prevention by concomite

administration of nerve growth factor. Brain Res 1978;141:105-18.
34 Apfel SC, Arezzo JC, Lipson L, Kessler JA. Nerve growth factor prevents experimental cisplatin neuropathy. Ann Neurol 1992;31:76-80.

35 Heumann $\mathrm{R}$, Lindholm D, Bandtlow C, et al. Differential regulation of mRNA encoding nerve growth factor and its receptor in rat sciatic nerve during development, degeneration, and regeneration: role of macrophages. Proc Natl Acad Sci USA 1987;84:8735-9.

36 Meyer M, Matsuoka I, Wetmore C, Olson L, Thoenen H. Enhanced synthesis of brain-derived neurotrophic factor in the lesioned peripheral nerve: different mechanisms are responsible for the regulation of BDNF and NGF mRNA. F Cell Biol 1992;119:45-54.

37 Friedman B, Scherer SS, Rudge JS, et al. Regulation of ciliary neurotrophic factor expression in myelin-related Schwann cells in vivo. Neuron 1992;9:295-305

38 Sendtner M, Stockli KA, Thoenen $\mathrm{H}$. Synthesis and localization of ciliary neurotrophic factor in the sciatic nerve of the adult rat after lesion and during regeneration. $\mathcal{f}$ Cell Biol 1992;118:139-48.

39 Curtis R, Scherer SS, Somogyi R, et al. Retrograde axonal transport of LIF is increased by peripheral nerve injury: correlation with increased LIF expression in distal nerve. Neuron 1994;12:191-204.

40 Cheema SS, Richards LJ, Murphy M, Bartlett PF. Leukaemia inhibitory factor prevents the death of axotomised sensory neurons in the dorsal root ganglia of the neonatal rat. F Neurosci Res 1994;37:213-8.

41 Cheema SS, Richards LJ, Murphy M, Bartlett PF. Leukaemia inhibitory factor rescues motoneurones from axotomy-induced cell death Neuroreport 1994;5:989-92.

42 Yip HK, Rich KM, Lampe PA, Johnson Jr. EM. The effects of nerve growth factor and its antiserum on the postnatal development and survival after injury of sensory neurons in rat dorsal root ganglia. $f$ Neurosci 1984;4:2986-92.

43 Yan Q, Elliott J, Snider WD. Brain-derived neurotrophic factor rescues spinal motor neurons from axotomy-induced cell death. Nature 1992;360:753-5.

44 Sendtner M, Kreutzberg GW, Thoenen H. Ciliary neurotrophic factor prevents the degeneration of motor neurons after axotomy. Nature $0 ; 345: 440-1$.

45 Chancellor AM, Warlow CP. Adult onset motor neuron disease: worldwide mortality, incidence, and distribution since 1950. $\mathcal{F}$ Neurol Neurosurg Psychiatry 1992;55:997-1001.

46 Chancellor AM. The Scottish motor neuron disease register: a prospective study of adult motor neuron disease in Scotland. Methodology, demography and clinical features of incident cases in 1989. F Neurol Neurosurg Psychiatry 1992;55:536-41.

47 Stockli KA, Lillien LE, Naher NM, et al. Regional distribution, developmental changes, and cellular localization of CNTF-mRNA and protein in the rat brain. $\mathcal{F}$ Cell Biol 1991;115:447-59.

48 Arakawa $Y$, Sedtner $M$, Thoenen $H$. Survival effect of ciliary neurotrophic factor (CNTF) on chick embryonic motoneurons in culture: comparison with

49 Oppenheim RW, Prevette D, Yin QW, Collins F, MacDonald J. Control of embryonic motoneuron survival in vivo by ciliary neurotrophic factor. Science 1991;251:1616-8.

50 Oppenheim RW. Cell death during development of the nervous system. Annu Rev Neurosci 1991;14:453-501.

51 Sendtner M, Arakawa Y, Stockli KA, Kreutzberg GW, Thoenen H. Effect of ciliary neurotrophic factor (CNTF) on motoneuron survival. $\mathcal{f}$ Cell Sci Suppl 1991;15:103-9.

52 Sendtner M, Schmalbruch H, Stockli KA, Carroll P, Kreutzberg GW, Thoenen $H$. Ciliary neurotrophic factor prevents degeneration of motor neurons in mouse mutant progressive motor neuronopathy [see comments]. Nature 1992;358:502-4.

53 Schmalbruch H, Jensen HJS, Bjaerg M, Kamieniecka Z, Kurland L. A new mouse mutant with progre

54 Masu Y, Wolf E, Holtmann B, Sendtner M, Brem G, Thoenen $H$. Disruption of the CNTF gene results in motor neuron degeneration. Nature 1993;365:27-32.

55 Takahashi R, Yokojii H, Misawa H, Hayashi M, Hu J, Deguchi T. A null mutation in the human CNTF gene is not causally related to neurological disease. Nature Genetics 1994;7:79-84.

56 Dittrich $\mathrm{F}$, Thoenen $\mathrm{H}$, Sendtner $\mathrm{M}$. Ciliary neurotrophic factor: pharm cokinetics and acute-phase response in rat. Ann Neurol 1994;35:151-63.

57 Hall AK, Rao MS. Cytokines and neurokines: related ligands and related receptors. TINS 1992;15:35-37.

58 Martinou J, Martinou I, Kato A. Cholinergic differentiation facto $[\mathrm{CDF} / \mathrm{LIF}]$ promotes survival of isolated rat embryonic motoneurons in vitro. Neuron 1992;8:737-44.

59 Richards L, Kilpatrick T, Bartlett P. Leukemia inhibitory factor promotes the neuronal development of the spinal cord precursors from the neura tube. F Neurosci Res 1992;33:476-84.

60 Murphy M, Reid K, Brown MA, Bartlett PF. Involvement of leukemia inhibitory factor and nerve growth factor in the development of dorsal root ganglion neurons. Development 1993;117:1173-82.

61 Hughes RA, Sendtner M, Thoenen H. Members of several gene families influence survival of rat motoneurons in vitro and in vivo. $\mathcal{F}$ Neurosci Res 1993;36:663-71.

62 Metcalf D, Nicola NA, Gearing DP. Effects of injected leukemia inhibitory factor on hematopoietic and other tissues in mice. Blood 1990;76:50-6.

63 Koliatsos VE, Clatterbuck RE, Winslow JW, Cayoutte MH, Price DI Evidence that brain-derived neurotrophic factor is a trophic factor for motor neurons in vivo. Neuron 1993;10:359-67.
64 Henderson CE, Camu W, Mettling C, et al. Neurotrophins promote motor neuron survival and are present in embryonic limb bud. Nature 1993;363:266-70.

65 Schecterson LC, Bothwell M. Novel roles for neurotrophins are suggested by BDNF and NT-3 mRNA expression in developing neurons. Neuron 1992;9:449-63.

66 DiStefano PS, Friedman B, Radziejewski C, Schnick C, Lindsay RM, Wiegand SJ. The neurotrophins BDNF, NT-3, and NGF display distinct patterns of retrograde axonal transport in peripheral and central neurons. Neuron 1992;8:983-93.

67 Klein R, Smeyne RJ, Wurst W, et al. Targeted disruption of the trkB Rers 75:113-22.

68 Enfors P, Lee KF, Jaenisch R. Mice lacking brain-derived neurotrophic factor develop with sensory deficits. Nature 1994;368:147-50.

69 Davies AM. Switching neurotrophin dependence. Current Biology 1994;4:273-6.

70 Hughes RA, Sendtner M, Goldfarb M, Lindholm D, Thoenen H Evidence that fibroblast growth factor 5 is a major muscle-derived survival factor for cultured spinal motoneurons. Neuron 1993;10:369-77.

71 Barinaga M. Neurotrophic factors enter the clinic. Science 1994;264: $772-4$.

72 Hyman C, Hofer M, Barde YA, et al. BDNF is a neurotrophic for the dopaminergic neurons of the substantia nigra. Nature 1991;350:230-2.

73 Hyman C, Juhasz M, Jackson C, Wright P, Ip NY, Lindsay RM. Overlapping and distinct actions of the neurotrophins BDNF, NT-3 and NT4/5 on cultured dopaminergic and GABAergic neurons of the ventral mesencephalon. $\mathcal{F}$ Neurosci $1994 ; 14: 335-47$.

74 Dal Toso R, Giorgio O, Soranzo C, Kirschner G. Development and survival of neurons in the dissociated fetal mesencephalic serum-free cell cultures. Effects of cell density and of adult mammalian striatal derived neurotrophic factor. $\mathcal{F}$ Neurosci $1988 ; 8: 733-45$.

75 Weigard SJ, Anderson K, Alexander C, et al. Receptor binding and axonal transport of I125-labelled neurotrophins in the basal ganglia and related brain regions. Mov Disord 1992;7(suppl 1):147B

76 Knusel B, Beck KD, Winslow JW, et al. Brain derived neurotrophic facto administration protects basal forebrain cholinergic but not nigral dopaminergic neurons from degenerative changes after axotomy. The Adult Rat Brain 1992;12:4391-402.

77 Altar CA, Boylan CB, Jackson C, et al. Brain derived neurotrophic factor augments rotational behaviour and nigrostriatal dopamine turnover invivo. Proc Natl Acad Sci USA 1992;89:11347-51.

78 Lin LFH, Doherty DH, Lile JD, Bektesh S, Collins F. GDNF: A glial cell line-derived neurotrophic factor for midbrain dopaminergic neurons. Science 1993;260:1130-2.

79 Stromberg I, Bjorklund L, Johansson M, et al. Glial cell line-derived neurotrophic factor is expressed in the developing but not adult striatum and stimulates developing dopamine neurons in vivo. Exp Neurol 1993;124:401-12.

80 Henry MA, Granholm AC, MacKerlovan L, Hudson J, Hoffer BJ, Collins F. Electron microscopic study following GDNF injection into the substantia nigra reveals sprouting and synaptogenesis within the striatum. Society for Neuroscience Abstracts 1993;275.4:652.

81 Hudson J, Granholm AC, Gerhardt G, et al. In-vivo activity of GDNF, a glial-cell-line derived neurotrophic factor, on the rat nigrostriatal dopamine system. Society for Neuroscience Abstracts 1993;275.5:652.

82 Ferrari G, Minozzi MC, Toffano G, Leon A, Skaper SD. Basic fibroblast factor affects the survival and development of mesencephalic neurons in culture. Dev Biol 1989;133:140-7.

83 Ferrari G, Minozzi MC, Toffano G, Leon A, Skaper SD. Basic fibroblast factor affects the survival and development of mesencephalic neurons in culture. Adv Exp Med Biol 1990;265:93-9.

84 Beck K, Knusel B, Hefti F. The nature of the trophic actions of brain derived neurotrophic factor, des(1-3)-insulin-like growth factor-I, and basic fibroblast growth factor on mesencephalic dopaminergic neurons developing in culture. Neuroscience 1993;52:855-66.

85 Alexi T, Hefti F. Trophic actions of transforming growth factor on mesencephalic dopaminergic neurons developing in culture. Neuroscience 1993;55:903-18.

86 Casper D, Mytilineou C, Blum M. EGF enhances the survival of dopamine neurons in rat embryonic mesencephalon primary cell culture. $\mathcal{f}$ Neurosci 1991;30:372-81.

87 Beal MF, Martin JB. Somatostatin: normal and abnormal observations in the CNS. In: Wurtman RJ, Corkin SH, Growdon JH, eds. Alzheimer disease: advances in basic research and therapies. Cambridge MA: Center for Brain Sciences and Metabolism Charitable Trust, 1984:229-58.

88 Sasaki H, Muramoto O, Kanazawa I. Regional distribution of amino acid transmitters in postmortem brains of presenile dementia of the transmitters in postmortem brains of pres

89 Korsching S, Auburger G, Heumann R, Scott J, Thoenen H. Levels of nerve growth factor and its mRNA in the central nervous system of nerve growth factor and its mRNA in the central nervous system
of the rat correlate with cholinergic innervation. EMBO $f$ 1985;4: 1389-3

90 Vazquez ME, Ebendal T. Messenger RNAs for trk and the low-affinity NGF receptor in the rat basal forebrain. Neuroreport 1991;2:593-6.

91 Crowley C, Spencer S, Nishimura M, et al. Mice lacking nerve growth factor display perinatal loss of sensory and sympathetic neurons yet develop basal forebrain cholinergic neurons. Cell 1994;76:1001-11.

92 Tuszynski MH, U HS, Amaral DG, Gage FH. Nerve growth factor infusion in primate brain reduces lesion-induced cholinergic neuronal degeneration. $₹$ Neurosci 1990;10:3604-14.

93 Koliatsos VE, Nauta HJ, Clatterbuck RE, Holtzman DM, et al. Mouse nerve growth factor prevents degeneration of axotomised basal forebrain cholinergic neurons in the monkey. $\mathcal{F}$ Neurosci 1990;10:3801-13.

94 Hefti F. Nerve growth factor promotes survival of septal cholinergic neurons after fimbrial transections. $\mathcal{F}$ Neurosci 1986;6:2155-62.

95 Williams LR, Varon S, Peterson GM, et al. Continuous infusion of nerve growth factor prevents basal forebrain neuronal death after fimbria fornix transection. Proc Natl Acad Sci USA 1986;83:9231-5.

96 Gage FH, Armstrong DM, Williams LR, Varon S. Morphological response of axotomised septal neurons to nerve growth factor. $\mathcal{F}$ Comp Neurol 1988;269:147-55.

97 Montero CN, Hefti F. Rescue of lesioned septal cholinergic neurons by nerve growth factor: specificity and requirement for chronic treatment.
$\mathcal{f}$ Neurosci $1988 ; 8: 2986-99$. 
98 Koliatsos VE, Applegate MD, Knusel B, et al. Recombinant human nerve growth factor prevents retrograde degeneration of axotomised basal forebrain cholinergic neurons in the rat. Exp Neurol 1991;112: 161-73.

99 Kawaja MD, Gage FH. Reactive astrocytes are substrates for growth for adult CNS axons in the presence of elevated levels of nerve growth factor. Neuron 1991;7:1019-30.

100 Otto D, Frotscher M, Unisicker K. Basic fibroblast growth factor and nerve growth factor administered in gel foam rescue medial septal neurons after fimbria fornix transection. F Neurosci Res 1989;22: 83-91.

101 Olson L, Norberg A, VonHolst $\mathrm{H}$, et al. Nerve growth factor affects 11C-nicotine binding, blood flow, EEG, and verbal episodic memory in Alzheimer patients. $\mathcal{F}$ Neural Transm 1992;4:79-95.

102 Mathews WB, Compston A, Allen IV, Martyn CN. Immunological aspects of multiple sclerosis. In: McAlpines's multiple sclerosis. aspects of multiple sclerosis. In: McAlpines

103 The IFN $\beta$ Multiple Sclerosis Study Group. Interferon beta-1b is effective in relapsing-remitting multiple sclerosis. I. Clinical results of a multicenter, randomised, double-blind, placebo-controlled trial. Neurology 1993;43:655-61.

104 Arnason BGW. Interferon beta in multiple sclerosis. Neurology 1993;43:641-3

105 Elias SB. Oligodendrocyte development and the natural history of multiple sclerosis. Arch Neurol 1987;44:1294-9.

106 Lassmann H. Comparative neuropathology of chronic experimental allergic encephalomyelitis and multiple sclerosis. In: Lassmann $\mathrm{H}$,

107 Althaus HH, Kloppner S, Schmidt-Shultz T, Schwartz P. Nerve growth factor induces proliferation and enhances fiber regeneration in growth factor induces proliferation and enhances fiber regeneration in oligodendrocytes

108 Raff MC, Miller RH, Noble M. A glial progenitor cell that develops in vitro into an astrocyte or an oligodendrocyte depending on the vitro into an astrocyte or an oligodend
culture medium. Nature $1983 ; 303: 390-6$.

109 Wolswijk G, Noble M. Identification of an adult-specific glial progenitor cell. Development 1989;105:387-400.

110 Noble $M$, Muray $K$, Stroobant $P$, Waterfield MD, Riddle P. Plateletderived growth factor promotes division and motility and inhibits derived growth factor promotes division and mocyte/type-2 astrocyte premature differentiation of the oligod

111 Raff MC, Lillien LE, Richardson WD, Burne JF, Noble MD. Plateletderived growth factor from astrocytes drives the clock that times oligc

112 Bogler O, Wren D, Barnett SC, Land H, Noble M. Cooperation between two growth factors promotes extended self-renewal an inhibits differentiation of O-2A progenitor cells. Proc Natl Acad Sci USA 1990;87:6368-72.

113 McKinnon RD, Matsui T, Dubois-Dalcq M, Aaronson SA. FGF modulates the PDGF-driven pathway of oligodendrocyte development. Neuron 1990;5:603-14.

114 Mayer M, Bogler O, Noble $M$. The inhibition of oligodendrocytic differentiation of $\mathrm{O}-2 \mathrm{~A}$ progenitors caused by basic fibroblast growth factor is overriden by astrocytes. Glia 1993;8:12-9.

115 Barres BA, Schmid R, Sendtner M, Raff MC. Multiple extracellular signals are required for long-term oligodendrocyte survival. Development 1993;118:283-95.

116 Mayer $M$, Bhakoo $K$, Noble $M$. Ciliary neurotrophic factor and leukemia inhibitory factor promote the generation, maturation and survival of oligodendrocytes in vitro. Development 1994;120:143-53.

117 Groves AK, Barnett SC, Franklin RJ, et al. Repair of demyelinating lesions by transplantation of purified O-2A progenitor cells. Nature 1993;362:641-3.

118 Metcalf D. Control of granulocytes and macrophages: molecular, cellular, and clinical aspects. Science 1991;254:529-33.

119 Reynolds B, Weiss S. Generation of neurons and astrocytes from isolated cells of the adult mammalian central nervous system. Science 1992;255:1707-10.

120 Richards L, Kilpatrick T, Bartlett P. De novo generation of neuronal cells from the adult mouse brain. Proc Natl Acad Sci USA 1992;89:8591-5. 